\title{
Interventions Supporting the Social Integration of Refugee Children and Youth in School Communities: A Review of the Literature
}

\author{
Andrew D. Reynolds \\ Rachel Bacon
}

\begin{abstract}
Schools function as a primary driver of integration and as a link to resources and assets that promote healthy development. Nevertheless, most research studies on school-based programs are conducted on mainstream students, and school professionals looking to deliver interventions serving refugee students are forced to choose between evidence-based programs designed for the mainstream and developing new programs in the cultural framework of their students. The purpose of this literature review is to provide a summary of recent research on successful, evidence-based programs as well as promising interventions and practice recommendations in five core practice areas in schools: school leadership and culture, teaching, mental health, after-school programming, and school-parent-community partnerships. These findings are presented drawing from theoretical frameworks of ecological systems, social capital, segmented assimilation, resilience, and trauma, and describe how such theories may be used to inform programs serving refugee children and youth. Additionally, this review describes the core components of successful programs across these practice areas to inform researchers and practitioners as they select and develop programs in their own school communities. Finally, this review concludes with a discussion of human rights in the education of refugee children and youth.
\end{abstract}

Keywords: Migration; refugees; children and youth; prevention

At the end of 2016, the number of forcibly displaced individuals worldwide reached a record high of 65.6 million people, 22.5 million of whom were formally recognized as refugees. Just over half of this worldwide refugee population is made up of children below 18 years of age (UNHCR, 2016). When refugee children flee their home countries, the lengthy process of displacement and resettlement can cause protracted periods of disruption, particularly in their education (Block, Cross, Riggs, \& Gibbs, 2014; McBrien, 2005; Naidoo, 2009; Nelson, Price, \& Zubrzycki, 2014). In schools, refugee students encounter academic and social challenges that may hinder processes of integration and healthy development (Bal \& Arzubiaga, 2014; Berthold, 2000; Kanu, 2008; Kia-Keating \& Ellis, 2007; Roy \& Roxas, 2011).

Schools function as a primary driver of integration and as a link to resources and assets that could promote the healthy development of refugee children. Nevertheless, most research on school-based programs are conducted on mainstream students, and school professionals looking to deliver interventions serving refugee students are forced to choose between evidence-based programs designed for the mainstream and developing new programs in the cultural framework of their students (Rousseau \& Guzder, 2008). As the number of refugees across the globe has reached historic highs and has been met with a

\footnotetext{
Andrew D. Reynolds, PhD, MSW, MEd is an Assistant Professor, School of Social Work, University of North Carolina at Charlotte, Charlotte, NC, 28223. Rachel Bacon, MSW, lives in Charlotte, NC. 
new wave of nativism and xenophobia among far-right movements (Minkenburg, 2013), there is a great need for evidence-based prevention programs in school communities that promote tolerance, encourage social integration, and enhance the health and well-being of refugee children. The purpose of this paper is (1) to provide a review of theoretical frameworks informing social work practice with refugee children in schools, (2) to examine existing evidence-based prevention programs in schools, (3) to identify core components of successful programs, and (4) to offer implications for social work research and practice with refugee children with an emphasis on education as a human right.

\section{Refugee Children}

Many refugee children have experienced violence or trauma prior to fleeing their countries of origin. Compared with adults, refugee children are at heightened risk for symptoms of posttraumatic stress disorder (PTSD), anxiety and depression, maladaptive grief, social withdrawal, and behavioral and academic difficulties (Halcon et al., 2004; Layne et al., 2008; Masten \& Narayan, 2012; Sullivan \& Simonson, 2016). Further, they must adjust to a completely new culture that includes new customs, a new language, and a new education system (Kia-Keating \& Ellis, 2007).

Once resettled, refugee children begin the challenging process of navigating a new educational environment. Many refugee students encounter academic, economic, and psychosocial challenges that include separation from family, cultural dissonance, acculturation stress, limited English proficiency, gaps in schooling, distrust or fear of school personnel, conflicting expectations between families and school faculty, and limited financial resources (Bal \& Arzubiaga, 2014; Berthold, 2000; Kanu, 2008; Kia-Keating \& Ellis, 2007; Roy \& Roxas, 2011). As a result, refugee youth are at higher risk for school dropout. In one longitudinal study, fewer than 2 in 3 refugee youth graduated high school, with age of arrival and experiences of discrimination as factors associated with dropout (Correa-Velez, Gifford, McMichael, Sampson, 2017).

Because school attendance is associated with developed fluency, many refugee children use these skills to function as cultural and lingusitic brokers for their families (McBrien, 2005). Students take on roles and responsibilities beyond their years and are burdened with leading their families in navigating the resettlement process. It is often students who are helping their parents build cross-cultural community and social networks, who serve as their interpreters, and who translate documents and correspondence for parents (Uptin, Wright, \& Harwood, 2013). These barriers and responsibilities may adversely affect refugee students' abilities to adjust and integrate successfully into a new schooling environment (Block et al., 2014).

There are a number of theoretical frameworks that can be used to understand the process of refugee resettlement and integration in school communities for refugee children and their families. Five theories are reviewed: ecological systems, social capital, segmented assimilation, resilience, and theories of trauma. 


\section{Ecological Systems Theory}

In the context of the resettlement of refugee children, ecological systems theory emphasizes the necessity of understanding the circumstances surrounding and affecting the resettlement and integration process. Ecological systems theory asserts that human development and behavior is a product of enduring forms of reciprocal interactions - called proximal processes - between individuals and their environments over time (Bronfenbrenner \& Morris, 2006). This ecological lens acknowledges that the traumatic and rapidly shifting events that occur before, during, and after flight from one's home country would disrupt and protract these very proximal processes necessary for a healthy course of development (Brenner \& Kia-Keating, 2017; McBrien, 2011; Rousseau \& Guzder, 2008). Difficulties surrounding the causes, processes, and effects of forced migration that occur in one area of an ecological system (e.g., the family) have consequences on other systems (e.g., the individual). Relationships may also be disrupted as a result of the varied reactions children have to the adversity they experience in forced migration. For example, youth exposed to war and violence commonly experience reactions that can burden their development, including symptoms of PTSD, anxiety, depression, grief, social withdrawal, externalizing behavior, separation anxiety, and ageinappropriate dependence on their caregivers (Berthold, 2000; Layne et al., 2008). These reactions to adverse experiences can disrupt the structures in the environments of children exposed to violence, persecution, and forced migration (Brenner \& Kia-Keating, 2017).

\section{Social Capital Theory}

Because forced migration fundamentally restructures social relationships for refugee children and families, the resettlement process also reduces access to the value and resources that come from relationships with others. Social capital theory argues that social relationships have value. For youth, social capital in the family, community, and school facilitate the development of new skills and capabilities, and may open doors to new opportunities and relationships (Coleman, 1988). However, individuals who are willfully or unintentionally excluded from these networks may not have access to the benefits that these relationships bring (Putnam, 1995). A social capital lens acknowledges the losses in access to resources and opportunities that refugee children experience as a result of forced migration, but also views rebuilding and fostering new positive relationships in order to recreate those resources and opportunities in the host country as a central goal of the resettlement process.

Schools are institutions that have the capacity to help foster the recreation of social capital for refugee children (Naidoo, 2009). As institutional agents, school personnel play a large role in both constructing and breaking down barriers to successful integration for refugee students (Stanton-Salazar, 2011). For refugee children to gain social capital and thrive, they need both social and institutional support from within the networks in which they interact, develop, and learn (Stanton-Salazar, 2011). 


\section{Segmented Assimilation Theory}

As refugee communities resettle in their host countries and adapt to a new culture, they may experience different pathways and outcomes of integration - one toward successful integration into the social and economic mainstream, and the other "downward assimilation" into a social underclass marked by deviance and reactive ethnicity subcultures (Haller, Portes, \& Lynch, 2011; Portes \& Zhou, 1993). Segmented assimilation theory argues that three factors - family structure, modes of incorporation, and access to human capital -determine the paths of mobility and integration for refugee communities, from the first to second and third generations and beyond. Given the numerous and complex challenges that are likely to occur throughout the resettlement and integration process, it is probable that resettled children will experience varying paths of acculturation that represent the range between successful integration and downward assimilation (McBrien, 2005). Disparities occurring in the three integration pathway determinants for refugee newcomers form into patterned difference over time. For example, factors such as low parental social and economic capital, hostile modes of incorporation in the receiving community, and weak co-ethnic communities, may lead to a particular path of downward assimilation for refugee children (Haller et al., 2011; Kanu, 2008). School systems may help buffer against these potential risks, or conversely form and reinforce negative pathway determinants for refugee children (Kanu, 2008). For example, discriminatory housing practices that disproportionately place refugee families in low-resource school communities may place refugee children in environments more reflective of Portes and Zhou's (1993) downward assimilation than successful integration into the middle class.

\section{Resilience Theory}

Nevertheless, refugee children are not entirely at the mercy of their circumstances. Resilience theory refers to the capacity of individuals to adapt to adversity and withstand or recover from challenges to one's development or security (Masten \& Narayan, 2012). Refugee children are part of a population the resilience literature identifies as "high-risk" due to the prevalence of adverse, stressful, and violent circumstances many of them endure prior to and throughout the resettlement process (Werner, 1995). Despite these detrimental experiences, there are multiple predictors for resilience in children, largely based on protective factors in individuals that can help moderate a person's response to adversity (Werner, 1995). Such protective factors can make a more profound impact on the lives of refugee children in comparison to their exposure risk factors and adverse life events (Werner, 1995).

Longitudinal studies on resilience have shown that during childhood and adolescence, factors such as social and problem-solving skills, a sense of autonomy, self-efficacy, a sense of purpose, creative interests, and religious beliefs may all promote positive adaptation to adversity (Benard, 2004). Protective factors in an individual's community may include family relationships as well as trusting relationships with teachers, neighbors, peers, and other positive role models (Werner, 1995). Schools play an important role in fostering resilience for refugee youth. For example, many refugee students possess high educational aspirations, which is a significant individual protective factor, and schools and 
their faculty can serve as protective agents at relational and environmental levels (Brenner \& Kia-Keating, 2017; Roy \& Roxas, 2011).

\section{Understanding Trauma}

Trauma, defined as an inescapable event that overwhelms an individual's existing coping mechanisms, is a common part of life experience for refugee populations (UNHCR, 2016). Trauma often follows in the wake of persecution, violence, conflict, and human rights violations in refugees' countries of origin. Experiences of trauma occur in multiple forms and are not limited to circumstances in refugees' countries of origin; trauma experiences can occur across pre-migration, migration, and resettlement periods (Weaver, 2016). Examples of pre-migration and migration trauma common to refugee experiences include lack of food or clean water, being displaced, lack of shelter, ill health without access to proper medical care, murder of a family member or other loved one, being detained or beaten, and witnessing war or violence (Sullivan \& Simonson, 2016; Weaver, 2016). Once refugee families are resettled in a country of origin, they may also experience psychological distress resulting from the difficulties of integrating into a new culture. The arduous process of acculturation is rife with potentially adverse circumstances, involving learning a new language, new customs, and navigating new social, financial, and educational systems (Sullivan \& Simonson, 2016).

The experience of trauma in the lives of refugee children can have lasting effects. Common child and adolescent responses to trauma may include fear, anger, irritability, sadness, apathy, inattention, anxiety, disrupted sleep, struggling in school, and somatic complaints, such as stomachaches and headaches (Sullivan \& Simonson, 2016). In a study conducted with Tamil refugees, most respondents reported that effects of their trauma experiences lingering after migration and resettlement included dwelling at length on their experiences, feeling hopeless, having recurring nightmares, and experiencing retraumatization as a result of triggers (Weaver, 2016). These responses reflect long-term behavioral and emotional effects of experiencing trauma, and they also reflect the brain's responses to trauma, even long after the traumatic event has actually occurred (Van der Kolk, 2014). When one experiences a traumatic event, the limbic system and brainstem in the lower parts of the brain respond to threat by triggering automatic reactions that may help a person reach safety (Nelson et al., 2014). These triggered bodily responses to trauma provide an adaptive and protective function at the time of the traumatic event; however, once these responses have become highly sensitive, similar reactions can be triggered again in situations that may seem similar but are not actually threatening. As a result, circumstances that recurrently trigger a response to distress can disrupt a person's day-today functioning (Nelson et al., 2014; Weaver, 2016).

In seeking to understand trauma among refugee children, it is important to exercise cultural sensitivity and recognize the many and diverse understandings of trauma. In Western countries, trauma is largely understood within a biomedical framework, which may be limited in its capacity to understand refugees as whole, diverse people who live lives that go far beyond the illness boundaries of the biomedical approach (Brough, Gorman, Ramirez, \& Westoby, 2003). A number of researchers argue that incorporating social factors and the recognition of self-healing capacities can help provide a lens of 
cultural humility and empowerment for refugee children who have experienced trauma (Brough et al., 2003; Evers, Van der Brug, Van Wesel, \& Krabbendam, 2016; Sullivan \& Simonson, 2016).

\section{Key Practice Areas in School-Based Interventions}

In light of these theoretical frameworks, the following section describes school-based interventions and recommended practices in five areas: school leadership and culture, teaching, mental health, after-school programs, and family and community partnerships.

\section{School leadership and culture}

School leadership and culture is a critical practice area for integration of refugee youth. School leaders have the capacity to create more culturally and linguistically responsive learning environments that promote the sociocultural integration of refugee youth. In a review of literature on school leadership, Khalifa, Gooden, and Davis (2016) identify four culturally responsive school leadership behaviors: developing critical self-awareness, supporting teachers in becoming more culturally responsive, creating culturally inclusive environments, and engaging parents and communities.

School leaders have the capacity to transform school environments to make them more inclusive and more responsive to the needs of refugee students. Scanlan and López (2014) argue that school leaders have three primary tasks in creating culturally and linguistically responsive schools: promote sociocultural integration, cultivate language proficiency, and ensure academic achievement. These goals are achieved by creating a learning architecture that creates and facilitates design for learning, which occurs in the context of communities of practice. By using the term learning architecture, Scanlan and Lopez (2014) argue that learning cannot be designed directly; rather school leaders are tasked to design for learning through the creation of processes and products that facilatate it. For educators looking to make their schools more responsive for refugee youth, the focus on learning architecture shifts the emphasis from what is "taught" to the structures in place within a school that facilitate cultural and lingusitic learning and exchange - both for teachers and students. For example, if a school leader wanted help their teachers develop culturally and linguistically reponsive teaching practices, the leader should focus not just on what is taught - e.g. a professional development training - but also on creating structures to faciltiate learning in an ongoing manner. Scanlan and Lopez (2014) argue that supportive teacher learning communities where teachers engage in regular and ongoing conversations about topics of pedagogy and cultural and linguistic difference provide an example of learning architecture in practice. The authors also argue that the practical elements of a learning architecture throughout a school community take form via integrated service delivery, which encompasses ensuring equal access to educational opportunities through high-quality teaching, resource allocation, and school policy.

Given the complexity of school leadership and the challenge of conducting randomized controlled trials at the school level, there are few evidence-based examples of school leadership practices that facilitate the integration of refugee youth beyond correlational or single case studies. One study across 44 schools in Melbourne, Australia used a mixed 
methods study that combined organizational ethnography, qualitative interviews, and quantitative tracking of refugee outcomes over time to evaluate an intervention called the School Support Programme for refugee youth (Block et al., 2014). The program involves creating a refugee action team at the school, comprised of teachers and members of the leadership and administration team. Each school completes a Refugee Readiness Audit, and in turn develops actions plans to address areas of need. Online resources and professional development opportunities are also included. Findings across the schools indicate promising results - many of the schools developed action plans and put them into action, changed school policies to make them more culturally responsive to refugee youth, and raised awareness among school teachers and staff about the challenges faced by refugees in the school system.

Two case-study examples also provide evidence of strategies that schools might use to create responsive communities for refugee students. In a study of four Australian schools, Taylor and Sidhu (2012) identify the importance of taking an advocacy role in school leadership through supporting students (particularly those unauthorized) through legal processes of immigration, accompanying families through the refugee review tribunal, and community advocacy efforts through newsletters and public statements in support of refugee well-being - even in some cases in response to less receptive language from politicians. The latter emphasizes the need to make the commitment to social justice for refugees explicit through school mission statements, values, and messaging. The authors acknowledge that systemic support via government-sponsored programs is critical to support these efforts. Additionally, a case-study of a South Australian primary schools emphasized the need for teacher trainings, curricular adjustments, and strategic decisions around integrating mainstream and newly arriving students by reducing tracking practices in classrooms and school activities (Pugh, Every, \& Hattam, 2012). More research is needed, however, to examine these practices at the district level in order to identify specific school leadership practices that help to effectively integrate refugee youth.

\section{Teaching}

Teachers play a primary role in the education and integration of refugee youth, yet research is mixed about the teacher's perceptions of refugee youth and the practices they use to work with this unique student population. A series of studies have examined teacher perceptions and beliefs about refugee children, each in unique social and political contexts. In a survey of 139 teachers in a large urban school district in the US Pacific Northwest, Kurbegovic (2016) found that teachers reported feeling confident and culturally competent to teach refugee students; however, many of these teachers did not believe that the needs and circumstances of these students were unique from those of mainstream students. Because of the significant barriers that culture, language, trauma, and migration play on refugee youth, teacher reports of confidence alongside a lack of acknowledgement of the needs of refugee students suggests a disconnect whereby teachers may be overconfident about their capacity to serve all of their students. This disconnect was also documented by Roy and Roxas (2011), who found that there was a strong disconnect between Somali Bantu families' goals and what their teachers thought their goals actually were, highlighting the ways in which teachers may have overemphasized the deficits of refugee 
families and played down or missed their strengths. In other research, teachers have been more direct about the need for additional supports. In a study of Norwegian teachers, Pastoor (2015) found that most teachers had neither sufficient knowledge nor competence to adequately account for the psychological problems that were presented by their refugee students, and expressed a need for more adequate teaching resources and supports. Similar sentiments are echoed in a study of teachers on Prince Edward Island who confirmed the need for additional professional development resources, particularly in the area of teaching in the context of trauma. One teacher described the process of teaching refugee students without adequate preparation as "like feeling your way around in the dark" (MacNevin, 2012).

Additionally, research has highlighted the work that teachers are doing in the classroom to reach refugee students. Windle and Miller (2012) used a survey research design to examine the extent to which teachers used commonly accepted language and literacy teaching pedagogies with refugee students, including practices such as scaffolding learners, using direct and explicit teaching of language, activating prior knowledge, modeling metacognitive skills, and focusing on critical and creative skills. Study findings indicate that over half of the practices they identified were used routinely by a majority of teachers. In light of research on teacher perceptions and beliefs about refugee students, such research suggests that overall teachers are using commonly accepted pedagogical strategies but that there is a knowledge and practice gap with respect to specific, tailored strategies for working with refugee students. One strategy for engaging refugee students can be to make more explicit the connection between students' lived experiences and classroom materials through the incorporation of "funds of knowledge" (Moll, Amanti, Neff, \& Gonzalez, 1992). Central to this approach is the understanding that households have cultural and cognitive resources useful for the classroom, and that teachers can use research strategies to engage with parents and households to qualitatively identify funds of knowledge at home that can then be used to augment teaching practices in the classroom. Szente, Hoot, and Taylor (2006) have also developed a series of recommendations for teachers in elementary settings working with refugee youth. These recommendations include: focusing on nonverbal social-emotional interventions, using peer learning strategies when possible, teaching mainstream youth about refugee experiences, and connecting to external resources.

\section{Mental and behavioral health}

Though refugee children are at heightened risk for a variety of mental and behavioral health problems (Halcon et al., 2004; Layne et al., 2008; Masten \& Narayan, 2012; Sullivan $\&$ Simonson, 2016), they are also less likely to seek out mental health treatment to address these challenges (de Anstiss, Ziaian, Procter, Warland, \& Bachurst, 2009; Ellis, Miller, Baldwin, \& Abdi, 2011). In one study in the Netherlands, $57.8 \%$ of refugee children were identified as in need of mental health services in comparison to only $8.2 \%$ of their native mainstream Dutch peers, and of these $57.8 \%$ only $12.7 \%$ actually accessed mental health services. Research has identified financial challenges, language and cultural concerns, parental health literacy, distrust of authority, differences in health care systems from the country of origin, and mental health stigma as factors preventing access to services for 
refugee children and families (Cardoso \& Lane, 2016; Ellis et al., 2011). Because children spend extensive time in school settings, schools may be a primary mechanism to identify and provide services for refugee youth in need of mental health services and may be a means through which psychoeducation and other strategies to raise awareness among refugee communities of the importance of seeking mental health services. Two reviews of prevention-based mental health programs exist (Rousseau \& Guzder, 2008; Tyrer \& Fazel, 2014), which identify cultural challenges and the heterogeneity of refugee populations and ethnicities as difficult challenges in this work, and also find evidence that interventions in which participants engage in verbal processing of prior experiences showed great promise. These reviews emphasize the heterogeneity of refugee experiences and gaps between school and family marked by language and culture, and note that clinical interventions for refugee mental health that include verbal processing of prior experiences had strong promise while significant changes in symptomatology are also observed for a number of creative arts interventions.

Some approaches to school-based mental health support use a multi-tiered systems of support (MTSS) framework. MTSS is a practice whereby teachers and school professionals match services according to a student's individual need according to three tiers (Winfrey Avant \& Lindsey, 2015). Tier 1 refers to universal services that all children receive, and often refers to school-wide programming and curricula. Tier 2 refers to more specialized services for a subset of students who need additional support, and finally tier 3 is associated with intensive services for students with high needs. Layne et al. (2008) conducted a randomized controlled trial of an integrative mental health program that used an MTSS framework in a school setting for war-exposed youth in Bosnia. The program included psychoeducation and coping skills for all children (tier 1), specialized trauma- and grieffocused intervention for youth with more severe needs and higher exposure to trauma (tier 2 ), and making referrals to community-based mental health providers outside the school for youth with acute levels of risk (tier 3). Reductions in PTSD and depression symptoms were observed for both the treatment (tier $1+2$ intervention) and the comparison (tier 1) groups and reductions in maladaptive grief were observed in the treatment group. Studies like these provide helpful guidance and offer examples of how schools might approach the mental health needs of war-exposed and refugee children through an MTSS approach, providing services to children based on their specific level of need. A similar study has also demonstrated that working with teachers to identify and refer students with specialized needs to external mental health providers can be a helpful model for addressing the mental health needs of refugee students (Fazel, Doll, \& Stein, 2009).

Cognitive behavioral therapeutic approaches have received some support in the literature as an intervention approach for refugee children with exposure to trauma (for a review, see Murray, Cohen, Ellis, \& Mannarino, 2008). A body of research examines how these approaches may be used in school-based mental health settings. One example is the "Children and War: Teaching Recovery Techniques" cognitive-behavioral psychosocial educational program, which is a manualized program that educates students about the symptoms of PTSD and teaches coping strategies to manage these symptoms. A recent randomized controlled trial of the intervention found clinically modest reductions in PTSD, behavioral problems, and challenging emotional symptoms, though these gains were not 
sustained at two-month follow-up (Ehntholt, Smith, \& Yule, 2015). Another school-based clinical trial in Sri Lanka also found that CBT coupled with creative arts activities helped reduce symptoms for boys and younger children, and children experiencing lower levels of war-related stressors, though the authors cautioned that the intervention may have disrupted natural processes of grieving for other children (Tol et al., 2012). Other research has examined the use of trauma-focused cognitive behavioral therapy (TF-CBT), an evidence-based treatment program for children and adolescents affected by trauma, with refugee populations. Unterhitzenberger Eberle-sejari, Rassenhofer, Sukale, and Rosner (2015) found promising findings in the use of TF-CBT in reducing post-traumatic stress with unaccompanied refugee minors in Germany, though the intervention was not conducted in a school setting. Another controlled trial compared TF-CBT with childcentered play therapy (CCPT) in 31 children in the US Northwest, finding that both intervention approaches reduced trauma symptoms (Schottelkorb, Doumas, \& Garcia, 2012). Other research suggests that TF-CBT can be modified slightly for work with refugee youth, including such practice strategies as providing a longer coping skills phase and allowing for adequate treatment closure phase for purposes of trust and safety (Cohen, Mannarino, Kliethermes, \& Murray, 2012).

Most school-based mental health interventions are delivered by mental health specialists (social workers, psychologists, counselors, or other support staff). However, one study developed a group-based cognitive-behavioral therapy intervention to be delivered by teachers to war-traumatized Syrian refugee children living in Istanbul, Turkey (Gormez et al., 2017). Due to a lack of resources and the challenges of recruiting Arabic-speaking mental health professionals in Turkey, the research team opted to train existing teachers to deliver an eight-week (70-90 minutes per session) group CBT intervention. Findings demonstrated reductions in anxiety and in intrusive and arousal symptoms of PTSD and provide promise for the capacity of school communities to train teachers to deliver mental health interventions.

Other approaches have also garnered attention in the literature, including narrative exposure therapy (Ruf et al., 2010), motivational interviewing (Potocky 2017), occupational therapy (Copley, Turpin, Gordon, \& Mclaren, 2011), and arts-based approaches (Rousseau, Drapeau, Lacroix, Bagilishya, \& Heusch, 2005; Yohani, 2008). In a clinical trial on the KIDNET narrative therapy for 7-16 year old refugee children with trauma backgrounds, researchers found clinical improvements in PTSD symptoms that were stable at 12-months follow-up, though this particular intervention did not take place in a school setting (Ruf et al., 2010). Narrative exposure therapy differs from other therapeutic approaches by encouraging the client to construct a narrative of their life's experiences while the clinician focuses on traumatic events within that narrative. In a recent practice brief, Potocky (2017) outlined strategies for using motivational interviewing with refugee youth, emphasizing the importance of a working alliance between practitioner and client that emphasizes collaboration, evocation, and autonomy, though future research is needed to examine the effectiveness of this practice with this population. Occupational therapy has also been used in school-based settings to assist in social and emotional skill development for refugee children, in which the occupational therapist works closely with the student's teacher to develop social skills - seeing occupational tasks as a means to skill 
development rather than as an end (Copley et al., 2011). Finally, a team of researchers in Canada have used arts-based approaches to assist refugee students, including the use of drama/theatre, visual arts and photography (Rousseau, Drapeau, Lacroix, Bagilishya, \& Heusch, 2005; Yohani, 2008). One of the advantages of such an approach is the nonstigmatizing, preventative nature of arts-based activities that allow for creative expression and affirmation of youth identities.

\section{After-school programs}

After-school programs (ASPs) have gained renewed attention as a mechanism for supporting students at-risk, in particular due to a recent meta-analysis that demonstrated the capacity of such programs to promote academic, personal, and social skills in children and adolescents (Durlak, Weissberg, \& Pachan, 2010). The authors of this study argue that while ASPs demonstrate great promise, effects are highest among programs with the following four criteria: sequenced, active, focused, and explicit ("SAFE"). Sequenced refers to having a clearly defined set of activities oriented toward a particular measurable outcome, active refers to the inclusion of active forms of learning, focused requires that programs have at least one component focused on personal/social skills, and finally explicit means that outcomes are specific and targeted.

Most research on ASPs focuses on mainstream children, and those that examine ASPs and migration in the United States have focused on immigrant, English-learning, and Latino/a groups, but not refugees specifically (Greenberg, 2013; McDonald et al., 2006; Park, Lin, Liu, \& Tabb, 2015). A set of studies have examined afterschool programming efforts for Hmong students including an arts-based theatre program (Ngo, 2017), a community-based program (Lee \& Hawkins, 2008), and a program developed through a school-community leadership model (Rah, 2013). Such programs provide examples of how schools and community-based organizations have the potential to build cultural bridges that may increase the participation in and success of afterschool programming for specific cultural groups. Additionally, Simpkins, Riggs, Ngo, Vest Ettekal, and Okamoto (2017) have developed specific culturally-responsive practice recommendations for youth programs in light of the growing cultural and linguistic diversity of children in the United States. Example recommendations include crafting explicit policies and procedures regarding inclusivity, creating leadership opportunities for all children regardless of background, structuring activities to foster community and avoid marginalization, and working with staff on areas of cultural responsiveness, awareness, and reduction of bias.

Still, the evidence of afterschool programming specifically for refugee youth remains scant. Some research in this area has used ethnographic or case-study approaches (Naidoo, 2009), describing how such programming may provide access to social and cultural capital and facilitate processes of inclusion. However, there is no research currently examining the effectiveness of such programs. In response to this gap in the literature, the authors are currently working with a local community agency to develop and evaluate an after-school program for refugee children. 


\section{School-family and school-community partnerships}

Connections between schools, parents, and communities play an important role in children's success in school, yet for families and children from refugee backgrounds these connections tend to be more tenuous, characterized by cultural misunderstanding and difference. Hornby and Lafaele (2011) have identified four primary barriers to parental involvement: parent and family factors (e.g., parent's perceptions beliefs about their involvement, life contexts), parent-teacher factors (differing goals, language differences), child factors, and societal factors. Research on refugee families specifically highlight similar themes, including differing expectations, perceptions, beliefs, and roles about parent involvement; language barriers; deference to authority in schools; and challenges associated with the process of resettlement (Georgis, Gokiert, Ford, \& Ali, 2014; McBrien, 2011; Rah, Choi, \& Nguyen, 2009; Roy \& Roxas, 2011).

Research on interventions to address these issues tend to be case studies with practice recommendations rather than clinical trials. This is generally due to the difficulty in conducting clinical trials with the school/program as the unit of analysis and the unique contexts that this subpopulation brings. In a recent paper, Georgis et al. (2014) recommend the inclusion of cultural brokers between schools and refugee parents, the development of reciprocal opportunities for involvement defined by both the school and parent communities, the fostering of trust and relationships, and being responsive to community needs as four strategies to consider when working with refugee parents. In interviews with school personnel working with Hmong migrants and refugees in Wisconsin, Rah et al. (2009) identified three concrete recommendations from the interviews: 1) creating a bilingual liaison position, 2) partnering with community organizations, and 3) parent education programs focused on issues related to their child's schooling in the United States. Themes of cultural brokerage, community partnership, and advocacy for parents were also present in other research in this area (McBrien, 2011; Taylor \& Sidhu, 2012).

\section{Core Components of Effective Programs}

While the approaches used by school professionals to improve the well-being of refugee students in this paper differ, there are common core components of successful programs and interventions across all five practice areas. Broadly, programs that include the presence of four recommended practices (sequenced, active, focused, and explicit) are likely to yield positive outcomes for youth from all backgrounds (Durlak et al., 2010). Yet there were other consistent characteristics of programs across practice areas unique to the experiences of refugee children and families. In general, programs were 1) tailored to the contexts of the program, and often to the specific cultural and linguistic backgrounds of a particular refugee subpopulation, 2) informed by the resettlement experience, in particular taking into consideration pre-migration, migration, and post-migration factors in designing program activities and intervention approaches, 3) embedded in community with strong linkages between parents, school leaders and community organizations, and 4) coordinated across multiple systems, whereby parent, school, and community leaders sought to use leadership and coordination strategies to draw upon the strength and expertise of multiple stakeholders to address challenges faced by refugee students. In most cases, programs 
opted to either adapt existing evidence-based programs for work with refugee students or develop their own program in light of best practices and research in this area.

\section{Education as a Human Right}

The U.N. Convention on the Rights of the Child has affirmed that education is a right and that this right is linked to equal opportunity and inclusion for all children regardless of background. While refugee children face the challenges of a difficult resettlement process, a host of cultural and linguistic barriers, social stigma, and exposure to trauma, it is important to recognize that these difficulties should not be used as an excuse for differential treatment or unequal access to learning opportunities. Social workers - in collaboration with government, schools, teachers, students, and parents, play a key role in ensuring that this right is protected and ensured for refugee children (Thomas, 2016). This is particularly important for social workers practicing in the United States, which has not ratified the U.N. Convention on the Rights of the Child - and where a recent court ruling affirmed that access to literacy is not a constitutionally protected right (Fortin, 2018). Ensuring this right not only works to advance the well-being of children on the margins, but works to serve the democratic goals of education oriented toward building a more just, inclusive, and equal society, consistent with the fourth Sustainable Development Goal of ensuring quality education for all.

What is less clear is how to ensure these rights are carried out at the school level. In contrast to what are called first-generation rights - typically civic and political rights such as the right to free speech - rights related to education are understood as second generation rights, which refer to the social, cultural, and economic rights that require positive action to be ensured by states (Willems \& Vernimmen, 2017). In many cases the historical and current political, cultural, and social realities of each state play an important role in the manner in which these rights are ensured (Willems \& Vernimmen, 2017). In Europe, for example, questions as to whether refugee students can be assessed additional fees, have a right to education in their native language, or can/should be placed in a separate learning environment provide examples of how the securing of second generation rights on the ground remain topics of social, cultural, and legal debate (Willems \& Vernimmen, 2017).

A second issue emerging with human rights and education relates to how the use of such rights are justified and implemented at the school level. McCowan demonstrates (2012) that the ways in which human rights are justified has important implications for both how human rights inform practice in school communities as well as the sustainability of those rights. For McCown, the inclusion of both status-based (deontological) and instrumental (consequential) justifications for supporting human rights provide learning opportunities where rights are upheld not solely for either their intrinsic value nor their instrumental effects, but both. Schools should promote human rights because they are of value in themselves, while also recognizing that the very justification of human rights provides an instrumental opportunity for learning that may make their incorporation in a school community more sustainable. Social workers might consider how the very act of supporting a school community in adopting a rights-respecting framework may in itself be an opportunity for learning. 


\section{Implications for Social Work Practice}

In offering a review of theory, evidence-based practice, and human rights, this review aims to provide insight as to how to approach social work practice with refugee students in school communities. While broad in scope, current research and practice efforts in these three areas have important implications for social work practice. In light of these efforts, the following recommendations are offered as potential starting points for working to ensure the welfare of refugee children and families in school communities.

1. Support teachers in providing knowledge about the refugee experience and the need for tailoring teaching practices to meet students where they are. Teachers need not develop entirely new teaching strategies, but should focus on incorporating knowledge of refugee children's experiences into their teaching practice. For example, teachers should support refugee students through homeschool communication, drawing on refugee family funds of knowledge (Moll, Amanti, Neff, \& Gonzalez, 1992), and engaging in goal-sharing strategies rooted in refugee family experiences.

2. Use an MTSS framework to develop a schoolwide plan for addressing the mental and behavioral health needs of all students, but in particular refugee students. At the first tier, this could involve psychoeducation programs as well as arts-based and other non-stigmatizing forms of school-based programming that affirm the cultures and identities of refugee students. At tiers 2 and 3, this could involve developing community relationships with mental and behavioral health providers, or conversely building a school-based mental health program with licensed clinicians who are experienced in working with children exposed to trauma.

3. Continue to develop new therapeutic approaches for working with refugee children, and build upon promising practice-based research on the effectiveness of trauma-focused cognitive behavioral approaches, play therapy, and narrative therapy.

4. Ensure that after-school programs are sequenced, active, focused, and explicit ("SAFE"). This may involve adapting or writing new curricula to help refugee students develop the social, emotional, and academic skills that will help them be successful in school.

5. Appoint bilingual liaisons and cultural brokers and support them financially when possible.

6. Develop community partnerships that foster mutual trust and provide access to resources to support refugee children in schools.

7. Continue to support a culture of research and evaluation in resettlement agencies and programs. In the United States, community-university partnerships may help develop this capacity at the local level and be particularly beneficial for small resettlement nonprofits with limited resources and expertise in research and evaluation. 
8. Make more effective use of administrative data systems. One key area is to advocate for the collection of refugee status (as distinct from immigration status or race/ethnicity) by local school districts, who can then use this information to provide aggregate data and reporting on the progress of refugee children in their district.

9. Continue to use evidence-based prevention programs designed for mainstream students across school communities, but tailor them when possible to meet the unique needs of refugee students without compromising program fidelity.

10. Avoid overemphasizing the need for more randomized controlled trials of culturally-tailored interventions, as they are often not reasonable and unrealistic. One strategy to address current research gaps would be to explicitly collect data on refugee status in conventional RCTs of mainstream interventions and use post-hoc tests to see if program outcomes are similar for refugee youth in comparison to their mainstream peers.

11. Advocate for the protection of funding for resettlement programs at the national level, and work with state agencies to ensure that funding supports for refugee children and families remains in the years following resettlement.

12. Work with district administrators and school principals to create a culture that maintains and promotes human rights at the district and school level. This work involes not only communicating human rights and making those rights explicit in district and school communities, but also the educational work of teaching human rights and providing avenues for "deep rooting" (McCowan, 2012, p. 78) and motivation for working to ensure these rights are correspondingly matched by practice and teaching efforts on the ground.

These recommendations are hardly exhaustive, but offer starting points for social workers and allied professionals in school communities to begin and continue the work of supporting the learning of refugee students.

One of the challenges of working to ensure second generation human rights like the right to education is that they require active promotion and support. Education systems need the appropriate funding and resources to carry out this work and ensure that human rights for all are realized. Another ethical document that may inform this work for social workers is the National Association of Social Workers Code of Ethics (2017). In particular, the document calls for social workers to take an active role in advocacy efforts:

Social workers should promote conditions that encourage respect for cultural and social diversity within the United States and globally. Social workers should promote policies and practices that demonstrate respect for difference, support the expansion of cultural knowledge and resources, advocate for programs and institutions that demonstrate cultural competence, and promote policies that safeguard the rights of and confirm equity and social justice for all people. (NASW, 2017, 6.04c) 
It is hoped that this review and the practice recommendations therein offer some guidance for practitioners looking to support the refugee children and families of their school communities.

\section{References}

Bal, A., \& Arzubiaga, A. E. (2014). Ahiska refugee families' configuration of resettlement and academic success in U.S. schools. Urban Education, 49(6), 635665. doi: https://doi.org/10.1177/0042085913481363

Benard, B. (2004). Resiliency: What we have learned. San Francisco, CA: WestEd.

Berthold, S. M. (2000). War traumas and community violence: Psychological, behavioral, and academic outcomes among Khmer refugee adolescents. Journal of Multicultural Social Work, 8(1,2), 15-46. doi: https://doi.org/10.1300/J285v08n01 02

Block, K., Cross, S., Riggs, E., \& Gibbs, L. (2014). Supporting schools to create an inclusive environment for refugee students. International Journal of Inclusive Education, 18(12), 1337-1355. doi: https://doi.org/10.1080/13603116.2014.899636

Brenner, M. E., \& Kia-Keating, M. (2017). Psychosocial and academic adjustment among resettled refugee youth. International Perspectives on Education and Society, 30, 221-249. doi: https://doi.org/10.1108/S1479-367920160000030016

Bronfenbrenner, U., \& Morris, P. A. (2006). The bioecological model of human development. In W. Damon \& R. Lerner (Eds.), Handbook of child psychology (pp. 793-828). New York: John Wiley \& Sons, Inc.

Brough, M., Gorman, D., Ramirez, E., \& Westoby, P. (2003). Young refugees talk about well-being: A qualitative analysis of refugee youth mental health from three states. Australian Journal of Social Issues, 38(2), 193-208. doi: https://doi.org/10.1002/j.1839-4655.2003.tb01142.x

Cardoso, J., \& Lane, L. (2016). Practice with immigrant and refugee children and families in the mental health system. In A. Dettlaff \& R. Fong (Eds.), Immigrant and refugee children and families: Culturally responsive practice (pp. 392-427). New York: Columbia University Press.

Cohen, J. A., Mannarino, A. P., Kliethermes, M., \& Murray, L. A. (2012). Traumafocused CBT for youth with complex trauma. Child Abuse \& Neglect, 36(6), 528541. doi: https://doi.org/10.1016/j.chiabu.2012.03.007

Coleman, J. S. (1988). Social capital in the creation of human capital. American Journal of Sociology, 94, S95-S120. doi: https://doi.org/10.1086/228943

Copley, J., Turpin, M., Gordon, S., \& Mclaren, C. (2011). Development and evaluation of an occupational therapy program for refugee high school students. Austrailian Occupational Therapy, 58(4), 310-316. doi: https://doi.org/10.1111/j.14401630.2011.00933.x

Correa-Velez, I., Gifford, S. M., McMichael, C., \& Sampson, R. (2017). Predictors of secondary school completion among refugee youth 8 to 9 years after resettlement in 
Melbourne, Australia. International Journal of Migration \& Integration, 18, 791805. doi: http://doi.org/10.1007/s12134-016-0503-Z

de Anstiss, H., Ziaian, T., Procter, N., Warland, J., \& Bachurst, P. (2009). Help-seeking for mental health problems in young refugees: A review of the literature with implications for policy, practice, and research. Transcultural Psychiatry, 46(4), 584607. doi: https://doi.org/10.1177/1363461509351363

Durlak, J. A., Weissberg, R. P., \& Pachan, M. (2010). A meta-analysis of after-school programs that seek to promote personal and social skills in children and adolescents. American Journal of Community Psychology, 45(3-4), 294-309. doi: https://doi.org/10.1007/s10464-010-9300-6

Ehntholt, K., Smith, P. A., \& Yule, W. (2015). School-based cognitive-behavioral therapy group intervention for refugee children who have experienced war-related trauma. Clinical Child Psychology and Psychiatry, 10(2), 235-250. doi: https://doi.org/10.1177/1359104505051214

Ellis, B. H., Miller, A. B., Baldwin, H., \& Abdi, S. (2011). New directions in refugee youth mental health services: Overcoming barriers to engagement. Journal of Child \& Adolescent Trauma, 4, 69-85. doi: https://doi.org/10.1080/19361521.2011.545047

Evers, S., Van der Brug, M., Van Wesel, F., \& Kbrabbendam, L. (2016). Mending the levee: How supernaturally anchored conceptions of the person impact on trauma perception and healing among children (cases from Madagascar and Nepal). Children \& Society, 30, 423-433. doi: https://doi.org/10.1111/chso.12153

Fazel, M., Doll, H., \& Stein, A. (2009). A school-based mental health intervention for refugee children: An exploratory study. Clinical Child Psychology and Psychiatry, 14(2), 297-309. doi: https://doi.org/10.1177/1359104508100128

Fortin, J. (2018, July 4). 'Access to literacy' is not a constitutional right, Judge in Detroit rules. New York Times (p. A11). Retreived from https://www.nytimes.com/2018/07/04/education/detroit-public-schoolseducation.html

Georgis, R., Gokiert, R., Ford, D., \& Ali, M. (2014). Creating inclusive parent engagement practices: Lessons learned from a school community collaborative supporting newcomer refugee families. Creating Inclusive Parent Engagement, Spring/Sum, 23-28.

Gormez, V., Kılıç, H. N., Orengul, A. C., Nursoy, M., Mert, E. B., Makhlouta, B., ... Semerci, B. (2017). Evaluation of a school-based, teacher-delivered psychological intervention group program for trauma-affected Syrian refugee children in Istanbul, Turkey. Psychiatry and Clinical Psychopharmacology, 27(2), 125-131. doi: https://doi.org/10.1080/24750573.2017.1304748

Greenberg, J. P. (2013). Determinants of after-school programming for school-age immigrant children. Children and Schools, 35(2), 101-111. doi: https://doi.org/10.1093/cs/cdt002 
Halcon, L. L., Robertson, C. L., Savik, K., Johnson, D. R., Spring, M. A., Butcher, J. N.,...Jaranson, J. M. (2004). Trauma and coping in Somali and Oromo refugee youth. Journal of Adolescent Health, 35, 17-25. doi: https://doi.org/10.1016/j.jadohealth.2003.08.005

Haller, W., Portes, A., \& Lynch, S. M. (2011). Dreams fulfilled, dreams shattered: Determinants of segmented assimilation in the second generation. Social Forces, 89(3), 733-762. doi: https://doi.org/10.1353/sof.2011.0003

Hornby, G., \& Lafaele, R. (2011). Barriers to parental involvement in education: An explanatory model. Educational Review, 63(1), 37-52. doi: https://doi.org/10.1080/00131911.2010.488049

Kanu, Y. (2008). Educational needs and barriers for African refugee students in Manitoba. Canadian Journal of Education, 31(4), 915-940.

Khalifa, M. A., Gooden, M. A., \& Davis, J. E. (2016). Culturally responsive school leadership: A synthesis of the literature. Review of Educational Research, 86(4), 1272-1311. doi: https://doi.org/10.3102/0034654316630383

Kia-Keating, M., \& Ellis B. H. (2007). Belonging and connection to school in resettlement: Young refugees, school belonging, and psychosocial adjustment. Clinical Child Psychology and Psychiatry, 12(29), 29-43. doi: https://doi.org/10.1177/1359104507071052

Kurbegovic, D. (2016). A survey study examining teachers' perceptions in teaching refugee and immigrant students. University of Washington. Retrieved from https://digital.lib.washington.edu/researchworks/handle/1773/36592

Layne, C. M., Saltzman, W. R., Poppleton, L., Burlingame, G. M., Pasalic, A., Durakovic, E.,...Pynoos, R. S. (2008). Effectiveness of a school-based group psychotherapy program for war-exposed adolescents: A randomized controlled trial. Journal of American Academy of Child and Adolescent Psychiatry, 47(9), 1048-1062. doi: https://doi.org/10.1097/CHI.0b013e31817eecae

Lee, S. J., \& Hawkins, M. R. (2008). "Family is here": Learning in community-based after-school programs. Theory Into Practice, 47(1), 51-58. doi: https://doi.org/10.1080/00405840701764763

MacNevin, J. (2012). Learning the way: Teaching and learning with and for youth from refugee backgrounds on Prince Edward Island. Canadian Journal of Education, 35(3), 48-63.

Masten, A. S., \& Narayan, A. J. (2012). Child development in the context of disaster, war, and terrorism: Pathways of risk and resilience. Annual Review of Psychology, 63(1), 227-257. doi: https://doi.org/10.1146/annurev-psych-120710-100356

McBrien, J. L. (2005). Educational needs and barriers for refugee students in the United States: A review of the literature. Review of Educational Research, 75(3), 329-364. doi: https://doi.org/10.3102/00346543075003329 
McBrien, J. L. (2011). The importance of context: Vietnamese, Somali, and Iranian refugee mothers discuss their resettled lives and involvement in their children's schools. Compare: A Journal of Comparative and International Education, 41(1), 75-90. doi: https://doi.org/10.1080/03057925.2010.523168

McCowan, T. (2012). Human rights within education: Assessing the justifications. Cambridge Journal of Education, 42(1), 67-81. doi: https://doi.org/10.1080/0305764X.2011.651204

McDonald, L., Moberg, D. P., Brown, R., Rodriguez-Espiricueta, I., Flores, N. I., Burke, M. P., \& Coover, G. (2006). After-school multifamily groups: A randomized controlled trial involving low-income, urban, Latino children. Children \& Schools, 28(1), 25-34. doi: https://doi.org/10.1093/cs/28.1.25

Minkenberg, M. (2013). The European radical right and xenophobia in West and East: Trends, patterns and challenges. In R. Melzer \& S. Serafin (Eds.), right-wing extremism in Europe: Country analyses, counter-strategies and labor-marketoriented exit strategies (pp. 9-34). Retrieved from http://library.fes.de/pdffiles/dialog/10031.pdf

Moll, L. C., Amanti, C., Neff, D., \& Gonzalez, N. (1992). Funds of knowledge for teaching: Using a qualitative approach to connect homes and classrooms. Theory Into Practice, 31(2), 132-141. doi: https://doi.org/10.1080/00405849209543534

Murray, L. K., Cohen, J. A., Ellis, B. H., \& Mannarino, A. (2008). Cognitive behavioral therapy for symptoms of trauma and traumatic grief in refugee youth. Child Adolescent Psychiatric Clinics of North America, 17, 585-604. doi: https://doi.org/10.1016/j.chc.2008.02.003

Naidoo, L. (2009). Developing social inclusion through after-school homework tutoring: A study of African refugee students in Greater Western Sydney. British Journal of Sociology of Education, 30(3), 261-273. doi: https://doi.org/10.1080/01425690902812547

National Association of Social Workers. (2017). Code of ethics of the National Association of Social Workers. NASW Press. Retrieved from https://www.socialworkers.org/About/Ethics/Code-of-Ethics/Code-of-Ethics-English

Nelson, D., Price, E., \& Zubrzycki, J. (2014). Integrating human rights and trauma frameworks in social work with people from refugee backgrounds. Australian Social Work, 67(4), 567-581. doi: https://doi.org/10.1080/0312407X.2013.777968

Ngo, B. (2017). Naming their world in a culturally responsive space. Journal of Adolescent Research, 32(1), 37-63. doi: https://doi.org/10.1177/0743558416675233

Park, H., Lin, C. H., Liu, C., \& Tabb, K. M. (2015). The relationships between afterschool programs, academic outcomes, and behavioral developmental outcomes of Latino children from immigrant families: Findings from the 2005 national household education surveys program. Children Services Review, 53, 77-83. doi: https://doi.org/10.1016/j.childyouth.2015.03.019 
Pastoor, L. D. W. (2015). The mediational role of schools in supporting psychosocial transitions among unaccompanied young refugees upon resettlement in Norway. International Journal of Educational Development, 41, 245-254. doi: https://doi.org/10.1016/j.ijedudev.2014.10.009

Portes, A., \& Zhou, M. (1993). The new second generation: Segmented assimilation and its variants. Annals of the American Academy of Political and Social Science, 530, 74-96. doi: https://doi.org/10.1177/0002716293530001006

Potocky, M. (2017). Motivational interviewing: A promising practice for refugee resettlement. Journal of Ethnic \& Cultural Diversity in Social Work, 25(3), 247-252. doi: https://doi.org/10.1080/15313204.2015.1028121

Pugh, K., Every, D., \& Hattam, R. (2012). Inclusive education for students with refugee experience: Whole school reform in a South Australian primary school. Australian Educational Researcher, 39, 125-141. doi: https://doi.org/10.1007/s13384-011-0048$\underline{2}$

Putnam, R. D. (1995). Bowling alone: America's declining social capital. Journal of Democracy, 6(1), [online only]. doi: https://doi.org/10.1353/jod.1995.0002

Rah, Y. (2013). Leadership stretched over school and community for refugee newcomers. Journal of Cases in Educational Leadership, 16(3), 62-76. doi: https://doi.org/10.1177/1555458913498479

Rah, Y., Choi, S., \& Nguyen, T. S. T. (2009). Building bridges between refugee parents and schools. International Journal of Leadership in Education, 12(4), 347-365. doi: https://doi.org/10.1080/13603120802609867

Rousseau, C., \& Guzder, J. (2008). School-based prevention programs for refugee children. Child and Adolescent Psychiatric Clinics of North America, 17(3), 533-549. doi: https://doi.org/10.1016/j.chc.2008.02.002

Rousseau, C., Drapeau, A., Lacroix, L., Bagilishya, D., \& Heusch, N. (2005). Evaluation of a classroom program of creative expression workshops for refugee and immigrant children. Journal of Child Psychology and Psychiatry and Allied Disciplines, 46(2), 180-185. doi: https://doi.org/10.1111/j.1469-7610.2004.00344.x

Roy, L., \& Roxas, K. C. (2011). Whose deficit is this anyhow? Exploring counter-stories of Somali Bantu refugees' experiences in "doing school." Harvard Educational Review, 81(3), 521-541. doi: https://doi.org/10.17763/haer.81.3.w441553876k24413

Ruf, M., Schauer, M., Neuner, F., Catani, C., Schauer, E., \& Elbert, T. (2010). Narrative exposure therapy for 7-to 16-year-olds: A randomized controlled trial with traumatized refugee children. Journal of Traumatic Stress, 23(4), 437-445. doi: https://doi.org/10.1002/jts.20548

Scanlan, M., \& López, F. (2014). Leadership for culturally and linguistically responsive schools. New York: Routledge. 
Schottelkorb, A. A., Doumas, D. M., \& Garcia, R. (2012). Treatment for childhood refugee trauma: A randomized, controlled trial. International Journal of Play Therapy, 21(2), 57-73. doi: https://doi.org/10.1037/a0027430

Simpkins, S. D., Riggs, N. R., Ngo, B., Vest Ettekal, A., \& Okamoto, D. (2017). Designing culturally responsive organized after-school activities. Journal of Adolescent Research, 32(1), 11-36. doi: https://doi.org/10.1177/0743558416666169

Stanton-Salazar, R. D. (2011). A social capital framework for the study of institutional agents and their role in the empowerment of low-status students and youth. Youth \& Society, 43(3), 1066-1109. doi: https://doi.org/10.1177/0044118X10382877

Sullivan, A. L., \& Simonson, G. R. (2016). A systematic review of school-based socialemotional interventions for refugee and war-traumatized youth. Review of Educational Research, 86(2), 503-530. doi: https://doi.org/10.3102/0034654315609419

Szente, J., Hoot, J., \& Taylor, D. (2006). Responding to the special needs of refugee children: Practical ideas for teachers. Early Childhood Education Journal, 34(1), 1520. doi: https://doi.org/10.1007/s10643-006-0082-2

Taylor, S., \& Sidhu, R. K. (2012). Supporting refugee students in schools: What constitutes inclusive education? International Journal of Inclusive Education, 16(1), 39-56. doi: https://doi.org/10.1080/13603110903560085

Thomas, R. L. (2016). The right to quality education for refugee children through social inclusion. Journal of Human Rights and Social Work, 1(4), 193-201. doi: https://doi.org/10.1007/s41134-016-0022-z

Tol, W. A., Komproe, I. H., Jordans, M. J., Vallipuram, A., Sipsma, H., Sivayokan, S., ... de Jong, J. T. (2012). Outcomes and moderators of a preventive school-based mental health intervention for children affected by war in Sri Lanka: A cluster randomized trial. World Psychiatry, 11(2), 114-122. doi: https://doi.org/10.1016/j.wpsyc.2012.05.008

Tyrer, R. A., \& Fazel, M. (2014). School and community-based interventions for refugee and asylum seeking children: A systematic review. PLOS ONE, 9(2), 1-12. doi: https://doi.org/10.1371/journal.pone.0089359

UNHCR. (2016). Global trends: Forced displacement in 2016. UNHCR: The UN Refugee Agency. Retrieved from http://www.unhcr.org/globaltrends2016/

Unterhitzenberger, J., Eberle-sejari, R., Rassenhofer, M., Sukale, T., \& Rosner, R. (2015). Trauma-focused cognitive behavioral therapy with unaccompanied refugee minors: A case series. BMC Psychiatry, 15, 1-9. doi: https://doi.org/10.1186/s12888$\underline{015-0645-0}$

Uptin, J., Wright, J., \& Harwood, V. (2013). 'It felt like I was a black dot on white paper': Examining young former refugees' experience of entering Australian high schools. Australian Educational Researcher, 40, 125-137. doi: https://doi.org/10.1007/s13384-012-0082-8 
Van der Kolk, B. (2014). The body keeps the score: Brain, mind, and body in the healing of trauma. New York: Penguin Group.

Weaver, H. N. (2016). Between a rock and a hard place: A trauma-informed approach to documenting the traumatic experiences of Tamil refugees. Journal of Human Rights and Social Work, 1, 120-130. doi: https://doi.org/10.1007/s41134-016-0013-0

Werner, E. E. (1995). Resilience in development. Current Directions in Psychological Science, 4(3), 81-85. doi: https://doi.org/10.1111/1467-8721.ep10772327

Willems, K., \& Vernimmen, J. (2017). The fundamental human right to education for refugees: Some legal remarks. European Educational Research Journal, 17(2), 1-14.

Windle, J., \& Miller, J. (2012). Approaches to teaching low literacy refugee-background students. Australian Journal of Language and Literacy, 35(3), 317-333.

Winfrey Avant, D., \& Lindsey, B. C. (2015). School social workers response to intervention change champions. Advances in Social Work, 16(2), 276-291. doi: https://doi.org/10.18060/16428

Yohani, S. C. (2008). Creating an ecology of hope: Arts-based interventions with refugee children. Child and Adolescent Social Work Journal, 25(4), 309-323. doi: https://doi.org/10.1007/s10560-008-0129-X

Author note: Address correspondence to: Andrew D. Reynolds, PhD, MSW, MEd School of Social Work, University of North Carolina at Charlotte, 9201 University City Blvd. Charlotte, NC 28223. areyno42@ uncc.edu 